\title{
Biodiversity in a Florida Sandhill Ecosystem
}

Samantha Robertson

University of South Florida

Advisors:

Arcadii Grinshpan, Mathematics and Statistics

Laurie Walker, Director of USF Botanical Gardens

Problem Suggested By: Seth Carlson

Field of Study for Problem Suggester: Environmental Scientist

Follow this and additional works at: https://digitalcommons.usf.edu/ujmm

Part of the Mathematics Commons

UJMM is an open access journal, free to authors and readers, and relies on your support:

Donate Now

\section{Recommended Citation}

Robertson, Samantha (2009) "Biodiversity in a Florida Sandhill Ecosystem," Undergraduate Journal of Mathematical Modeling: One + Two: Vol. 2: Iss. 1, Article 6.

DOI: http://dx.doi.org/10.5038/2326-3652.2.1.6

Available at: https://digitalcommons.usf.edu/ujmm/vol2/iss1/6 


\title{
Biodiversity in a Florida Sandhill Ecosystem
}

\begin{abstract}
This project compares two transects of land in the University of South Florida's Botanical Gardens for their biodiversity. The transects were chosen to represent a Florida sandhill ecosystem and the individual Longleaf Pine, Saw Palmetto, Turkey Oak, Laurel Oak and Live Oak specimens were counted. All other species above waist height were counted as "other"?. Once the individuals were counted, the Simpson's and Shannon-Wiener indices were calculated. Since the Shannon-Wiener index incorporates several diversity characteristics, it is typically more reliable than Simpson's. However, both biodiversity indices agreed that transect $B$ was more diverse than transect $A$.
\end{abstract}

\section{Keywords}

Biodiversity, Simpson's Index, Shannon- Wiener Index, Florida Ecosystems

\section{Creative Commons License}

(c) (i) ()

This work is licensed under a Creative Commons Attribution-Noncommercial-Share Alike 4.0 License. 


\section{TABLE OF CONTENTS}

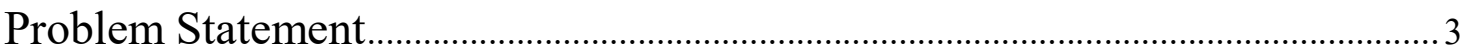

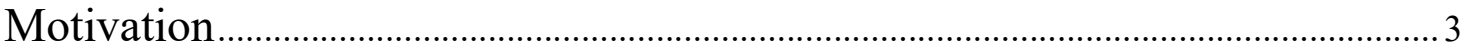

Mathematical Description and Solution Approach .................................................

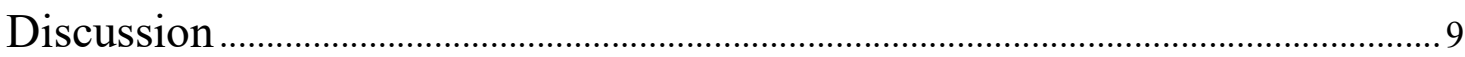

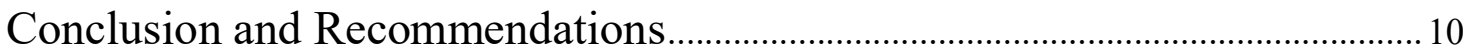

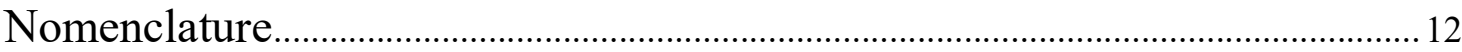

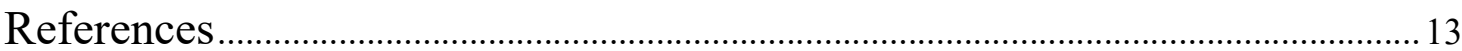

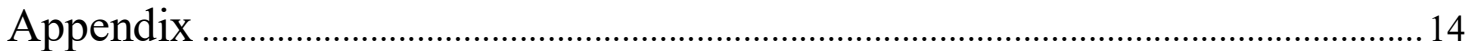




\section{PROBLEM STATEMENT}

The objectives of this project are

1. Describe and explain biodiversity trends and gradients on a local scale,

2. List the flora associated with the Florida sandhill ecosystem, and

3. Calculate various biodiversity indices.

\section{MOTIVATION}

This project was motivated by an interest in environmental science, Florida ecosystems and mathematics. Calculating biodiversity is essential in environmental science and ecology because it helps scientist to determine the overall health of an ecosystem as well as the human impact on a community. Biodiversity levels can provide information on other subjects such as fire frequencies, animals, plants, soils, and water. This project describes the biodiversity found in two transects of land in the University of South Florida's Botanical Gardens which were chosen based on elements representative of a high pine or sandhill Florida ecosystem.

Longleaf Pine (See Picture 1) and many different types of oak (See Pictures 3, 4, 5) are species indicative of a sandhill (high pine) ecosystem. Myers describes this ecosystem by an "open overstory of Longleaf Pine, deciduous oak underwood and herbaceous groundcover" (Myers, p. 177). Trees of the sandhill ecosystem are characterized by their fire resistance and intolerance of high water tables. Fires play an important role in clearing out the dead undergrowth, exposing fresh soil which seeds need in order to grow. Since Longleaf Pine and other oaks are intolerant of higher water tables found elsewhere in Florida, they are mainly found 

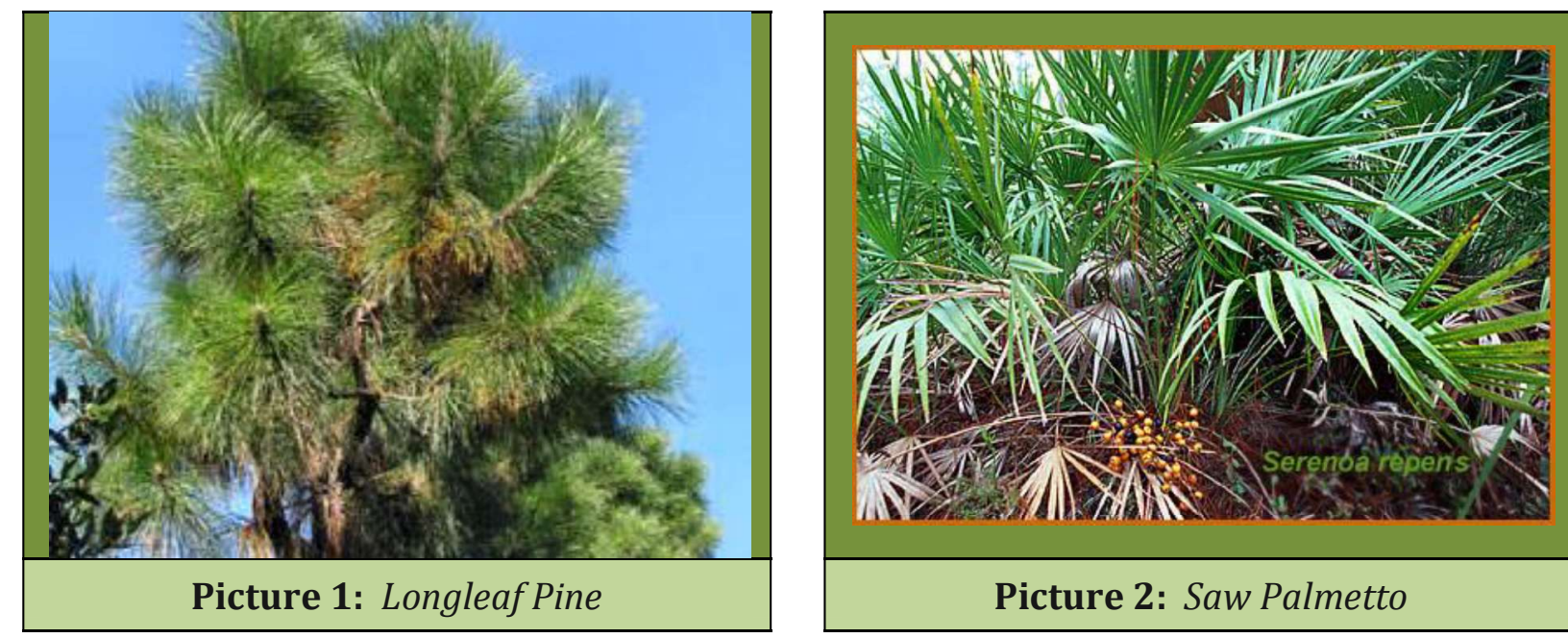

Picture 1: Longleaf Pine

Picture 2: Saw Palmetto

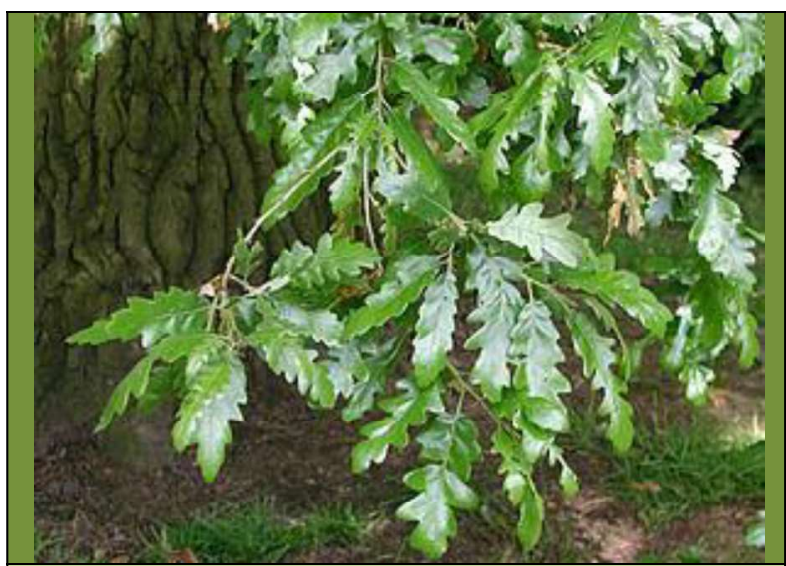

Picture 3: Turkey Oak

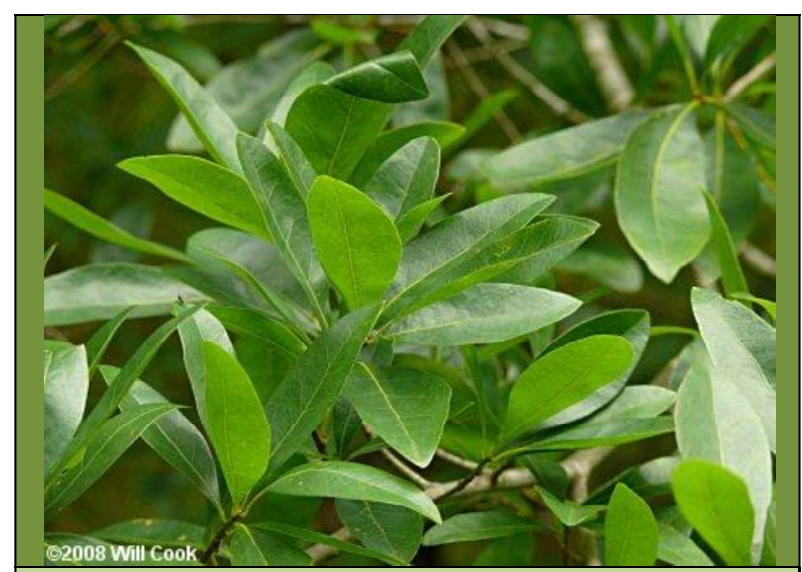

Picture 4: Laurel Oak

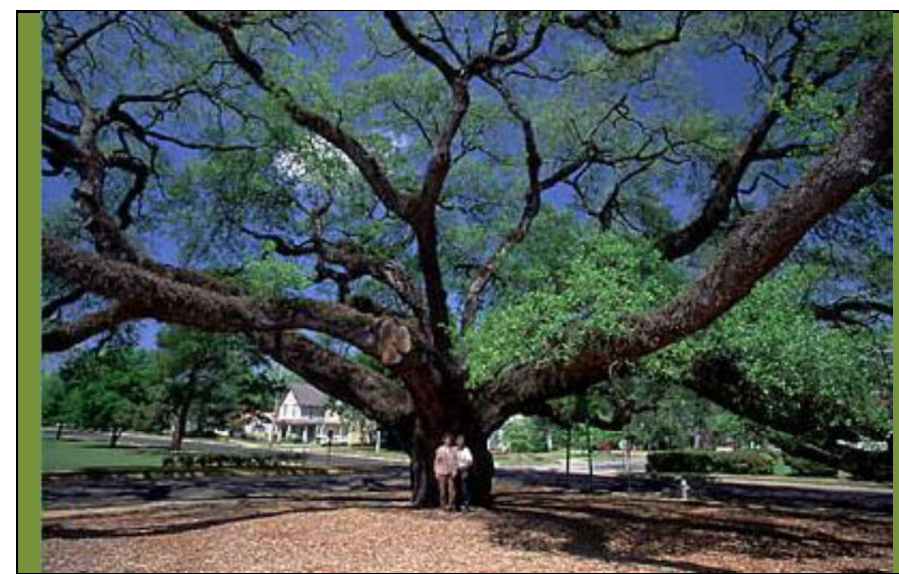

Picture 5: Live Oak 
in the center of Florida (Lake Wales Ridge) and the region extending from northern Florida to Virginia.

For this project, only the dominant tree species of the high pine ecosystem were included in the biodiversity calculation. The mathematic tools used in this project include summations, the Cauchy-Schwartz inequality and logarithms. Statistical approaches are also discussed as a method of determining the biodiversity in a large, partially uncountable sample set.

\section{MATHEMATICAL DESCRIPTION AND SOLUTION APPROACH}

Two transects in the University of South Florida's Botanical Gardens were chosen for sampling. After collecting data, the Simpson's Index $(D)$ and the Shannon-Wiener Index $\left(H^{\prime}\right)$ were used to determine which transect is more diverse. Both indices were chosen for their use in research as well as their reliability. The Simpson's Index $(D)$ employs use of data regarding the proportion of the species while the Shannon-Wiener Index $\left(H^{\prime}\right)$ includes information on species evenness and richness. These indices take quantitative numbers and express them into qualitative terms. This being so, neither index uses units. As such, the two indices cannot be compared to one another. The $D$ value for transect A can be compared to the $D$ value for transect B, while the $H^{\prime}$ value of transect A can be compared to the $H^{\prime}$ value of transect B (See Tables 1 and 2), but the $D$ value of transect A can not be compared to the $H^{\prime}$ value of transect A and likewise with the $D$ and $H^{\prime}$ values of transect B (See Table 1).

The Simpson's Index used for calculating the diversity is as follows:

$$
D=1-\sum p_{i}^{2}
$$


where $p_{i}$ is the proportion of species $i$ in the community. The proportion is found by dividing the number of individuals per species by the total number of individuals in the transect. The Simpson's Index measures the probability that two individuals chosen at random will be the same species. Because of this, the range for the Simpson's Index is from zero to one. Zero is the least diverse and one is the highest level of diversity attainable with this index.

According to Krebs (1985), the Shannon-Wiener Index $\left(H^{\prime}\right)$ calculates the heterogeneity of a community using the number of species in the community and the number of individuals in each species. The Shannon-Wiener Index is given by:

$$
H^{\prime}=\left|\sum_{i=1}^{n} p_{i} \ln p_{i}\right|
$$

where $\ln p_{i}$ is the natural logarithm of $p_{i}$. From Tables 1 and 2 in the Appendix, the Simpson's Index and Shannon-Wiener as summarized as:

\section{Transect A Transect B}

\begin{tabular}{|r|rr|}
\hline Simpson's Index $(D)$ & 0.73 & 0.76 \\
\hline Shannon-Wiener Index $\left(H^{\prime}\right)$ & 1.43 & 1.55 \\
\hline
\end{tabular}

Notice that both indices designate Transect B to have greater biodiversity.

On a side note, an upper bound for the Simpson's Index can be achieved through the use of the Cauchy-Schwartz inequality which states that for

$$
\left(\sum_{k=1}^{n} a_{k} b_{k}\right)^{2} \leq\left(\sum_{k=1}^{n} a_{k}^{2}\right)\left(\sum_{k=1}^{n} b_{k}^{2}\right)
$$

When $a_{i}=p_{i}$ and $b_{i}=1$ for all $1 \leq i \leq n$, equation (3) becomes

$$
\left(\sum_{k=1}^{n} p_{k}\right)^{2} \leq n \sum_{k=1}^{n} p_{k}^{2}
$$

and using the fact that $\sum_{k=1}^{n} p_{k}=1$ the upper bound for Simpson's Index is 


$$
D_{\max }=1-\sum p_{i}^{2} \leq 1-\frac{1}{n}=\frac{n-1}{n} .
$$

Similarly, an upper bound for the Shannon-Wiener Index occurs when all species are of equal abundance.

$$
H_{\text {max }}^{\prime} \leq\left|\sum_{i=1}^{n} \frac{1}{n} \ln \frac{1}{n}\right|=\left|n\left(-\frac{1}{n} \ln n\right)\right|=\ln n
$$

For this experiment, $D_{\max }=\frac{5}{6} \approx 0.833$ and $H_{\text {max }}^{\prime}=\ln 6 \approx 1.791$.

Simpson's Index and the Shannon-Wiener Index may be computed as finite or infinite sums. For example, in a small study area where only larger, immobile species are being considered (such as the cases for this project) finite series are appropriate. In fact, all cases where it is possible to count every species despite their variety in size and mobility, finite series are most appropriate. However, scientists need to keep in mind that there are an infinite number of species (i.e. insects and other arthropods, lichens, fungi, etc) which can not be counted precisely.

A community will have a small number of species which are common and a greater number of species that are rare and "a variety of statistical distributions can be fitted to data on the relative abundances of species." (Krebs, 514). Two common statistical distributions used to model uncountable species are the "hollow curve" distribution and the "bell curve" distribution. Both statistical techniques amount to estimating the number of species present in an ecosystem based on statistics mirrored in similar ecosystems.

By fitting data to a "hollow curve," (See Figure 1) Fisher, Corbet and Williams were able to determine the relative abundance of moths and butterflies in England based on quantity caught in their light traps. They caught a total of 197 species from a sample of 6,814 individuals. Of the 


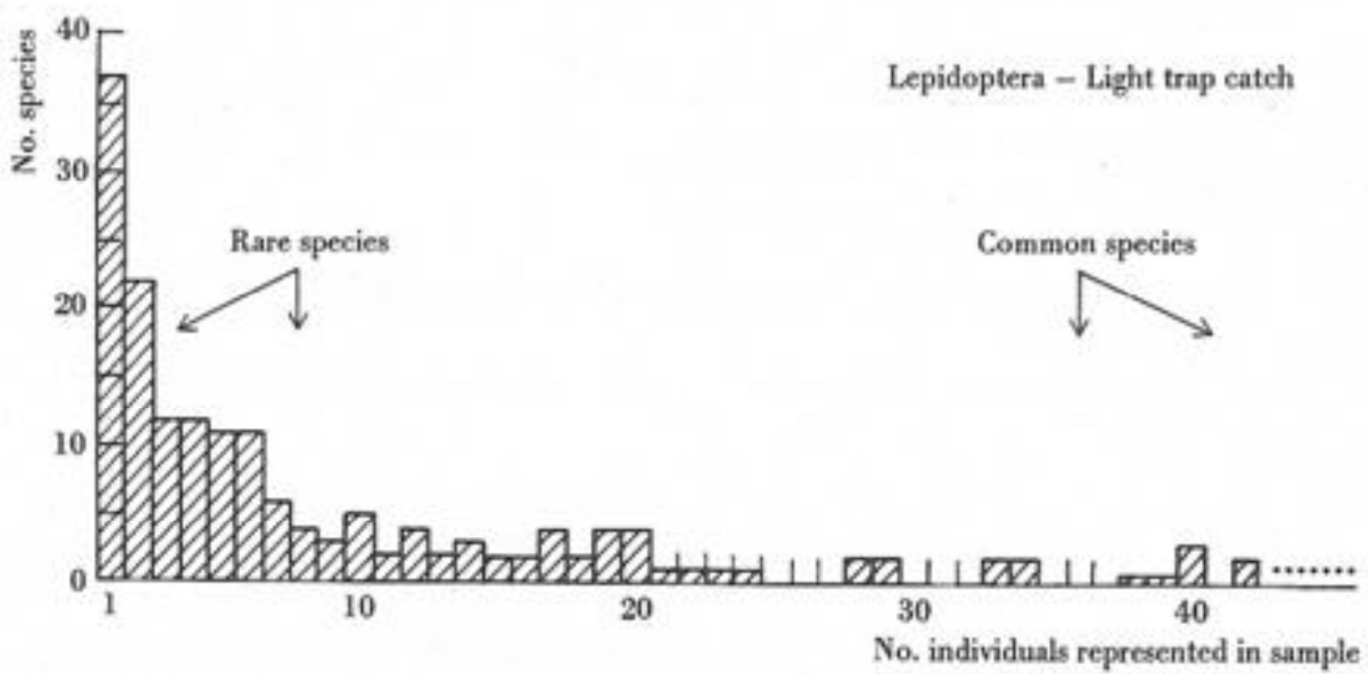

Figure 1: Number of individual butterflies/moths per species collected in Fisher, Corbet and William's experiment.

total 197 species, 37 species were sampled with just one individual, and 1,799 individuals were collected from one species. Overall, six species accounted for $50 \%$ of the total individuals. This being so, they concluded that more species are represented by one individual than species represented by numerous individuals. Plotting this data gave them a "hollow curve" that tapers off to the right as the species become more common (Krebs, 514).

Another common statistical model used to describe an uncountable species population is the "bell curve." Most species' populations within communities follow a log-normal distribution, or "bell curve." A theoretical model, such as the log-normal distribution, can account for other rare species that may not have been counted in the original sample set. Once the experimental data is expressed as a probability distribution, adjustments can be made to predict population increases over time (See figure 2). As the population grows, the bell shifts to the right without changing shape. Since this distribution is common to many communities where the total number of species is large, it is the "expected statistical distribution for many biological communities" 


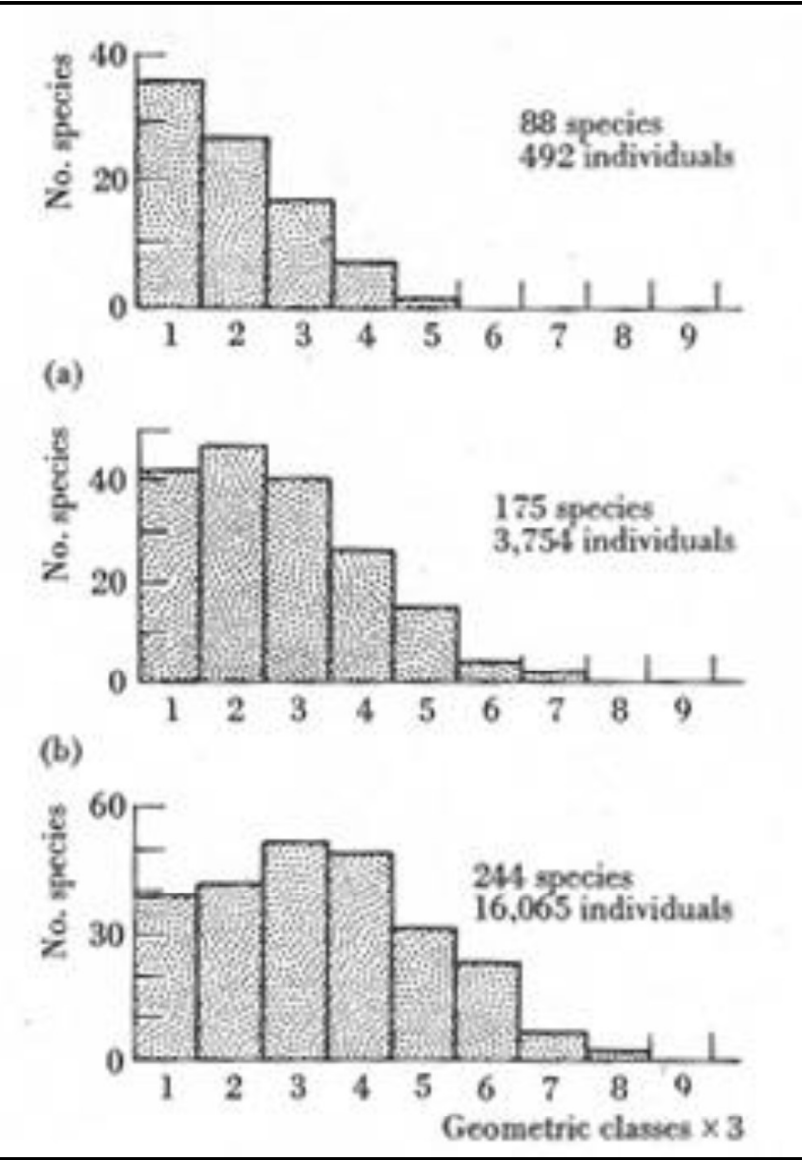

Figure 2: Log normal distribution at 1/8 year, 1 year, and 4 years from Fisher, Corbet and Williams.
(Krebs, 517). It is important to remember that some very rare species may not be counted empirically or theoretically if the sample size is too small, however large samples may not be conducive to the experiment at hand.

Measuring biodiversity can be as simple as counting the total number of species present in a community or may involve more complex calculations such as the Simpson's Index $(D)$ or the ShannonWiener Index $\left(H^{\prime}\right)$. Statistical methods can account for uncountable or infinite populations in ecology and environmental science. Calculating biodiversity is a large

part of determining the health of an ecosystem, and is important in environmental science.

\section{DISCUSSION}

The Simpson's Index only considers the "probability that two individuals picked at random belong to the same species," or species richness (Bloch, 49) and common species have more influence than rare species. In this study, the Shannon-Wiener Index was also calculated to give a better understanding of the diversity of the two transects. The Shannon-Wiener Index is more reliable than the Simpson's Index because both species richness and evenness are 
considered. According to Krebs, "a greater number of species increases species diversity, and a more even or equitable distribution among species will also increase species diversity" for the Shannon-Wiener Index (Krebs, 521). It is important to note that both indices are well established with ample research backing their applications to ecology and environmental science.

One may suspect that transect A would contain a higher biodiversity based on the fact that transect B contains more species, but both the Simpson's index and the Shannon-Wiener index agree to the contrary. Transect A had a $D$ value of 0.73 and an $H^{\prime}$ value of 1.43 whereas transect B had a $D$ value of 0.76 and an $H^{\prime}$ value of 1.55 . Even though transect A had fewer total species, their distribution was more uniform than those of transect B. This suggests that transect B was more diverse.

Since the 63 individuals in transect A were not evenly distributed between the six species measured, transect A was determined to be less diverse. Although transect B only had a total of 33 individuals, it was more diverse because the individuals were more evenly distributed among each species (See Tables 1 and 2).

\section{CONCLUSION AND RECOMMENDATIONS}

The objectives of the project were met: Information on vegetation found in a Florida sandhill ecosystem was documented, biodiversity trends and gradients were examined, and biodiversity indices were calculated. Of the two transects examined, transect B was more diverse.

In this study, six species were counted but, in theory, an infinite number of species could be considered using infinite series in the indices. Ecosystems such as coral reef have a large number of species living in close proximity and it may be impossible to count all of the 
individuals present. A finite series based on the species observed may be used to establish an infinite series which assigns a small population proportion for the species not observed. In such a

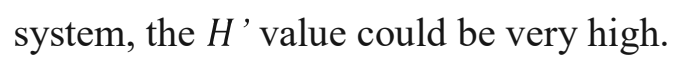

Should this project be conducted again, it would be a good idea to use larger transects. A larger study area would achieve more accurate results. Also, fauna could be included in the species list. Animal species often cannot live without certain plant species. For example, the gopher tortoise is largely dependant on the "sandy soils, herbaceous plants and open sunny areas" found in the sandhill ecosystem (Bloch, 48). Plant and animal species are usually codependent, so measuring the animal interaction with the ecosystem could provide information on the plant species as well.

It is recommended that future studies: include a larger number of species, use larger transects, or explore several varied ecosystems to measure the overall diversity in Florida. 


\section{NOMENCLATURE}

\begin{tabular}{|cll|}
\hline Symbol & Name & \multicolumn{1}{c|}{ Notes } \\
\hline$p_{i}$ & Species Proportion & $\begin{array}{l}\text { Proportion of individuals in a species to the } \\
\text { number of individuals in a transect. }\end{array}$ \\
\hline $\ln x$ & Natural Logarithm & The logarithm function with base $e$. \\
\hline$D=1-\sum p_{i}{ }^{2}$ & Simpson's Index & Ranges from 0 (Low) to 1 (High). \\
\hline$H^{\prime}=\left|\sum p_{i} \ln p_{i}\right|$ & Shannon-Wiener Index & Diversity increases as $H^{\prime}$ increases. \\
\hline
\end{tabular}




\section{REFERENCES}

Bloch, Jonathan. Introduction to Environmental Science Lab Manual. $9^{\text {th }}$ ed. USF Dept. of Environmental Science and Policy, 2009.

Myers, R.L. 1990. Scrub and High Pine, pgs in Ecosystems of Florida (eds. R.L. Myers and J.J Ewel). University of Central Florida Press: Orlando.

Krebs, C.J. 1985. Ecology- the Experimental Analysis of Distribution and Abundance, $3^{\text {rd }}$ edition. HarperCollins Publishers, Inc: New York, NY.

Fisher, R.A., A.S. Corbet, C.B. Williams. "Relative abundance if Lepidoptera (butterflies and moths) captured in light trap in Rothamsted, England, in 1935." Photograph. (1943). Rpt. in Ecology- the Experimental Analysis of Distribution and Abundance. New York: HarperCollins Publishers, Inc, 1985. 514. Print.

Fisher, R.A., A.S. Corbet, C.B. Williams. "Log normal distributions of the relative abundances of Lepidoptera insects captured in light traps at Rothamsted Experimental Station, England." Photograph. (1943). Rpt. in Ecology- the Experimental Analysis of Distribution and Abundance. New York: HarperCollins Publishers, Inc, 1985. 514. Print.

"Longleaf Pine (Pinus palustris)." Photo. Alabama State Tree Southern Longleaf Pine. 28 Sept 2009. 14 Dec 2009.

$<$ http://www.netstate.com/states/symb/trees/alsouthern_longleaf_pine.htm>.

"Saw palmetto (Serenoa repens)." Photo. Florida Forest Plants. 14 Dec 2009.

$<$ http://www.sfrc.ufl.edu/4h/Saw_palmetto/sawpalme.htm>.

Emley, Dave. "Turkey Oak - Quercus cerris.” Photo. Keele University Arboretum. 13 Oct 2009. 14 Dec 2009.

$<$ http://www.keele.ac.uk/university/arboretum/trees/turkey_oak.htm>.

Robeson. "Laurel Oak (Quercus laurifolia).” Photo. Duke University. 29 May 2008. 14 Dec 2009.

$<$ http://www.duke.edu/ cwcook/trees/qula.html $>$.

"Live oak (Quercus virginiana)." Photo. Florida Forest Trees. 14 Dec 2009.

$<$ http://www.sfrc.ufl.edu/4h/live_oak/liveoak.htm>. 


\section{APPENDIX}

\begin{tabular}{|r|ccccc|}
\hline \multicolumn{1}{|c|}{ Species } & Count & $p_{i}$ & $p_{i}{ }^{2}$ & $\ln p_{i}$ & $p_{i} \ln p_{i}$ \\
\hline Longleaf Pine & 0 & 0.00 & 0.00 & --- & -- \\
\hline Saw Palmetto & 6 & 0.10 & 0.01 & -2.30 & -0.23 \\
\hline Turkey Oak & 3 & 0.05 & 0.00 & -2.20 & -0.15 \\
\hline Laurel Oak & 24 & 0.38 & 0.15 & -0.97 & -0.37 \\
\hline Live Oak & 16 & 0.25 & 0.06 & -1.39 & -0.35 \\
\hline Other & 14 & 0.22 & 0.05 & -1.51 & -0.33 \\
\hline Totals & 63 & & 0.27 & & -1.43 \\
\hline Simpson's Index $(D): 0.73$ & Shannon-Weiner Index $\left(H^{\prime}\right): 1.43$ \\
\hline
\end{tabular}

Table 1: Biodiversity in Transect A

\begin{tabular}{|r|ccccc|}
\hline \multicolumn{1}{|c|}{ Species } & Count & $p_{i}$ & $p_{i}{ }^{2}$ & $\ln p_{i}$ & $p_{i} \ln p_{i}$ \\
\hline Longleaf Pine & 8 & 0.24 & 0.06 & -1.42 & -0.34 \\
\hline Saw Palmetto & 1 & 0.03 & 0.00 & -3.50 & -0.11 \\
\hline Turkey Oak & 2 & 0.06 & 0.00 & -2.80 & -0.17 \\
\hline Laurel Oak & 3 & 0.09 & 0.01 & -2.40 & -0.22 \\
\hline Live Oak & 10 & 0.30 & 0.09 & -1.19 & -0.36 \\
\hline Other & 9 & 0.27 & 0.07 & -1.30 & -0.35 \\
\hline Totals & 33 & & 0.24 & -1.55 \\
\hline Simpson's Index $(D): 0.76$ & Shannon-Weiner Index $\left(H^{\prime}\right): 1.55$ \\
\hline
\end{tabular}

Table 2 : Biodiversity in Transect B 